\title{
UMA VISÃO INTEGRADA DOS PROCEDIMENTOS DISCURSIVOS DIDÁTICOS DE UM FORMADOR EM SITUAÇÕES ARGUMENTATIVAS DE SALA DE AULA*
}

\section{An integrated view of the discourse of a teacher trainer in argumentative situations in a classroom}

\author{
Rodrigo Drumond Vieira ${ }^{1}$ \\ Silvania Sousa do Nascimento ${ }^{2}$
}

Resumo: Neste artigo, com base em uma pesquisa concluída de pós-graduação, de cunho etnográfico, realizada num contexto de formação inicial de professores de física, examinamos e discutimos o escopo de um conjunto de Procedimentos Discursivos Didáticos (PDD) que um professor formador experiente utiliza para gerenciar situações argumentativas de sala de aula. Com isso, procuramos demonstrar a característica exemplar desses Procedimentos e a forma específica de sua repercussão no discurso argumentativo, tanto na sua fase de abertura quanto no seu desenvolvimento e fechamento. Por fim, sugerimos a necessidade de ampliação de pesquisas que colaborem para a construção de um quadro de Procedimentos Discursivos Didáticos e a sua integração em estruturas relacionais de modo a estabelecer referências para os professores em situações argumentativas de sala de aula.

Palavras-chave: Formação de professores de Física. Interações discursivas. Argumentação. Procedimentos discursivos didáticos.

\begin{abstract}
In this work, from a post graduate ethnographic investigation within the context of preservice physics teacher education, we try to examine and discuss the design of the whole discoursive pattern that an experienced teacher trainer uses to control classroom argumentative situations. With it, we try to demonstrate the exemplary characteristic of this pattern and its specific repercussions in the argumentative discourse, both on its opening phase and in its development and closure. Finally, we suggest the need for investigations that contribute to constructing a set of Discursive Didactic Proceedings and the integration into relational frameworks to establish references for teachers in argumentative situations in classrooms.
\end{abstract}

Keywords: Preservice Physics teacher education. Discursive interactions. Argumentation. Didactic discursive proceedings.

\footnotetext{
* Apoio CNPq, Capes, Fapemig.

${ }^{1}$ Licenciado em Física; Doutorando em Educação, Faculdade de Educação, Universidade Federal de Minas Gerais (UFMG), Belo Horizonte, MG, Brasil. rodrigo_vdrumond@yahoo.com.br

${ }^{2}$ Licenciada em Física, Doutora em Didactique des Disciplines; Docente, Departamento de Métodos e Técnicas de Ensino, Faculdade de Educação, UFMG. Belo Horizonte, MG, Brasil. silvania.nascimento@gmail.com
} 


\section{Introdução}

Cada vez mais as pesquisas conduzidas em sala de aula têm incorporado em seu programa a função especial da linguagem e do seu papel nos processos de ensino e aprendizagem. Os estudos conduzidos segundo esse enfoque buscam apoio nos trabalhos de Vygotsky (2000) e Bakhtin (2000), os quais asseveram que os processos característicos da cognição humana estão profundamente associados à aquisição e ao uso da linguagem em contextos específicos. Nessa perspectiva, a linguagem passa a ser considerada como ferramenta de pensamento, e não apenas expressão de um pensamento anterior e mais fundamental.

A capacidade de ponderar entre diferentes pontos de vista e de justificá-los segundo um campo semântico específico são competências consideradas necessárias ao desenvolvimento do pensamento crítico e, consequentemente, ao exercício da cidadania do homem contemporâneo. Assim, reconhecemos a argumentação, que se caracteriza justamente pela presença de contradições e justificativas de pontos de vista (BILLIG, 1996), enquanto um discurso fortemente relacionado ao desenvolvimento de tais competências. A educação formal, por sua vez, representa um espaço privilegiado para o desenvolvimento de estratégias que busquem incorporar a argumentação em sala de aula segundo orientações pedagógicas específicas. Tal possibilidade repousa nas tensões e divergências presentes nesse espaço, as quais, por sua vez, são fruto tanto da diversidade semântica específica das grades curriculares, que cada vez mais buscam integrar temas transversais, quanto da própria heterogeneidade constitutiva do espaço de sala de aula.

Existe razoável literatura sobre a argumentação considerando o contexto da Educação Básica (ALEIXANDRE e AGRASO, 2006; CAPPECHI e CARVALHO, 2004; VILLANI e NASCIMENTO, 2003; VILLANI, 2002; SANTOS, MORTIMER e SCOTT, 2001). Entretanto, há relativamente poucos estudos referentes às situações argumentativas levando em conta a Educação Superior (MUNFORD et al., 2005; ANDRÉ, 2002), especialmente a formação de professores de ciências. Tais lacunas são preocupantes, uma vez que consideramos que deve haver um conhecimento de tais situações de modo a gerar propostas pedagógicas destinadas a aproximar as práticas argumentativas da Educação Superior e Básica, contribuindo para integrá-las de maneira dialética. Ou seja, não adianta somente considerarmos as práticas argumentativas em sala de aula da Educação Básica se os próprios formadores de professores de ciências se mostram alheios a tais práticas no contexto de suas disciplinas.

Em suma, um conhecimento dessa natureza na formação de professores de ciências seria de fundamental importância para que, além oferecer subsídios para propostas curriculares e pedagógicas que incorporem e busquem aperfeiçoar as práticas discursivas argumentativas, sirva também para instrumentar os licenciandos e propiciar aproximações entre as práticas deles e as do próprio formador.

Além disso, considerando que diferentes formas de interações discursivas em contextos específicos podem levar a diferentes conceitualizações de um mesmo fenômeno ou conteúdo do currículo (CANDELA, 1999), torna-se de particular interesse para a pesquisa o papel do professor em situações discursivas de ensino e aprendizagem: a maneira de se gerenciar e controlar o discurso em sala de aula está diretamente associada aos modos de construção de conhecimento pelos alunos referentes a tópicos do conteúdo curricular.

Em concordância com esse quadro referencial, o corpus analisado neste trabalho inscreve-se numa pesquisa concluída de mestrado (VIEIRA, 2007), de cunho etnográfico, que 
buscou compreender as situações argumentativas na abordagem da Natureza da Ciência na formação inicial de professores de física. Procuramos considerar tais situações em sua condição espontânea, ou seja, sem a intervenção intencional do pesquisador. Com isso pretendíamos construir um conhecimento sobre as situações argumentativas na formação inicial de professores de física de modo a levar em conta e preservar a complexidade e multiplicidade inerentes a tais situações.

Orientados por esses propósitos, decidimos concentrar nossa pesquisa na disciplina Prática de Ensino de Física I (PEF I), focando os procedimentos e as práticas do formador nas situações argumentativas. A escolha da disciplina se pautou na nossa percepção dela enquanto um espaço em que há convivência entre diversos campos do saber, o que seria favorável a possíveis rupturas e divergência de domínios de saberes entre os licenciandos e entre eles e o formador, ou seja, o ambiente seria favorável a contradições - elemento que, segundo Billig (1996), é central a toda argumentação.

No contexto em que realizamos a pesquisa, de uma grande universidade pública do sudeste do país, a disciplina PEF I é obrigatória para todos os alunos do curso de Licenciatura em Física. As aulas da disciplina acontecem duas vezes por semana, com duração aproximada de uma hora e quarenta minutos cada. A grade curricular da disciplina engloba várias áreas de conhecimento do campo pedagógico e, em especial, do ensino de ciências. O estágio de observação de trinta horas, que faz parte da disciplina, é realizado fora da carga horária semanal de aula, e executado geralmente em duplas, em escolas escolhidas pelos licenciados de acordo com suas conveniências e disponibilidades.

Considerando nosso objetivo em caracterizar as situações discursivas argumentativas na PEF I, decidimos selecionar um formador experiente e pesquisador do discurso em sala de aula, o que, na nossa perspectiva, se refletiria em práticas e ações exemplares na condução e coordenação das situações argumentativas. Com isso, neste trabalho buscamos explicitar tais práticas do formador na forma de Procedimentos Discursivos Didáticos (PPD), constituindo, por hipótese, um conhecimento pedagógico que possa servir de referência para outros formadores quando confrontados com situações argumentativas estabelecidas ou potenciais.

Em suma, buscaremos destacar e discutir um conjunto de Procedimentos Discursivos Didáticos do formador relacionando-os com a dinâmica discursiva estabelecida em sala de aula. Com isso, pretendemos mostrar que esses Procedimentos podem servir como meios para se atingir e gerenciar determinados discursos e, assim, servir como recursos para cumprir determinados propósitos ligados às situações discursivas em sala de aula, em especial, à argumentação.

\section{A argumentação e os procedimentos discursivos didáticos em sala de aula de prática de ensino de Física}

Van Eemeren, Grootendorst e Kruiger (1987) compreendem a argumentação como uma atividade social, intelectual e verbal, consistindo em uma constelação de proposições dirigida no sentido de obter a aprovação de um auditório sobre um determinado assunto por meio de argumentos colocados para justificar ou refutar uma ou várias opiniões. Com isso, os autores deixam explícito o caráter persuasivo inerente a toda argumentação. Devido a esse 
Vieira, R. D.; Nascimento, S. S.

aspecto persuasivo que não pode ser negligenciado, compreendemos que a contraposição de ideias e o uso de justificativas são elementos constitutivos de toda situação argumentativa (VIEIRA e NASCIMENTO, 2009; BILLIG, 1996).

De acordo com tais posicionamentos, tomamos a contraposição de ideias como indicador de situações argumentativas no contexto da PEF I, uma vez que avaliamos que a contraposição de ideias é um indicador explícito de que a situação discursiva em pauta destina-se ao convencimento.

Conforme apresentado em Vieira e Nascimento (2007) e Nascimento e Vieira (2008), em seguida à identificação das situações argumentativas, recorremos ao padrão de Toulmin (1958) como ferramenta analítica, a qual se mostrou muito importante para a pesquisa, pois nos possibilitou avaliar de maneira mais clara a forma de articulação lógica entre as proposições na construção de um determinado argumento e, consequentemente, as suas relações externas com outros argumentos. Assim, foi possível, com o auxílio do padrão, distinguir determinados procedimentos do formador como Procedimentos Discursivos Didáticos (PDD). Nesse processo procuramos evidenciar semelhanças e diferenças entre os argumentos do formador e dos licenciados, e dos argumentos do formador em diferentes contextos, de modo a possibilitar o estabelecimento de contrastes.

Coerentemente com as proposições de Candela (1999) mencionadas anteriormente, Mortimer e Scott (2002) apontam que é de fundamental importância a capacidade do professor de controlar o "ritmo" de ensino em sala de aula, o qual está associado às variações do discurso produzido nessas situações. Relacionados a essa capacidade, os PDD seriam aqueles em que o formador estabelece, no discurso e num dado momento, uma intervenção discursiva que repercute concretamente, gerando mudanças nesse discurso. Se considerarmos que tais mudanças são didaticamente informadas e, além disso, colaboram para direcionar e gerenciar o discurso, então se pode supor que as apresentações e discussões situadas dos PDD podem servir de referência para outros formadores e professores em situações discursivas, especialmente a argumentação.

\section{Procedimentos metodológicos}

A coleta de dados durante a pesquisa de mestrado envolveu observação sistemática com auxílio do caderno de campo e de gravação em vídeo de quase todo curso de PEF I durante um semestre letivo. Além disso, realizamos duas entrevistas semiestruturadas com o formador: a primeira foi realizada antes da coleta de dados e teve como objetivo nos fornecer uma primeira aproximação do contexto da PEF I. A segunda entrevista foi realizada ao final da coleta de dados e buscou checar as percepções do formador acerca dos episódios que selecionamos para análise em microescala, ou seja, ela trabalhou com a questão da memória discursiva.

Realizamos duas análises: em macro e em microescala. A primeira escala nos serviu como uma contextualização geral para os elementos analisados na segunda escala. Ou seja, a análise em macroescala buscou situar em um contexto mais amplo (em tópicos e ações principais do formador em cada aula, em uma escala de tempo de vários minutos) o contexto de produção dos argumentos que foram analisados em microescala (em uma escala de tempo de vários segundos e alguns minutos). A análise em macroescala foi realizada a partir da adapta-

446

Ciência \&̊ Educaşão, v. 15, n. 3, p. 443-457, 2009 
ção de Freitas (2002) do quadro de apresentação dos dados (VIEIRA, 2007). Esse quadro apresenta várias colunas: uma coluna para marcar os principais tópicos da aula observada; uma coluna com marcador (a contraposição de idéias) para os trechos das situações argumentativas; por fim, as colunas restantes são marcadores de tempo e identificação das aulas.

O quadro foi construído com base na análise da integralidade das aulas filmadas e da identificação de contraposição de ideias e do tema em discussão. Assim, para a coluna marcadora da argumentação, toda vez em que houve mudança de tema, marcamos o fim do trecho considerado, definindo, com isso, a sua duração. Dada a complexidade das situações conversacionais, as nossas notas do caderno de campo de observação também nos auxiliaram nessa identificação. A partir desse quadro selecionamos três episódios para a análise em microescala. Os nossos critérios de seleção se pautaram em características dos episódios que, em seu conjunto, seriam favoráveis em preservar, na nossa análise, um pouco da diversidade e complexidade dos domínios de conhecimentos discutidos nas situações argumentativas ocorridas, além de possibilitarem, também, o estabelecimento de contrastes.

A partir do registro em vídeo, inicialmente realizamos a transcrição primária de todos os três episódios e, em seguida, uma segunda transcrição em quadros proposicionais (VIEIRA e NASCIMENTO, 2007; VIEIRA, 2007), em que cada proposição corresponde à menor unidade de sentido do discurso. Tais quadros, tanto devido ao seu aspecto visual quanto ao caráter unitário de sentido de cada proposição, nos facilitaram a realização da análise em microescala, em que enquadramos os enunciados em argumentos segundo o padrão de Toulmin (1958). $\mathrm{Na}$ sequência e com o auxílio dos enquadramentos, buscamos identificar um conjunto de PDD do formador nos episódios selecionados. É importante mencionar que a nossa identificação e demarcação de cada argumento específico se deram em função das recomendações de Kuhn (1993) acerca do papel fundamental dos contra-argumentos para a produção de novos argumentos.

Neste artigo apresentamos a discussão de cinco PDD presentes em um mesmo episódio e buscamos relacioná-los com os três momentos discursivos principais do episódio em que ocorreram: momentos de abertura, desenvolvimento e fechamento. Com isso, pretendemos revelar os "lugares" que tais PDD ocupam, nos diferentes momentos da estrutura discursiva das situações argumentativas selecionadas. Para tanto e por questões de espaço, evitaremos explicitar toda a dinâmica discursiva do episódio em que os PDD se situam. Antes, faremos o esforço de indicar as características mais marcantes dos PDD e explicitar como tais características lhes permitem se situarem mais coerentemente em um determinado momento discursivo do que em outro. Além disso, tratados enquanto unidades de análise, os PDD servirão para entender e acompanhar a dinâmica argumentativa estabelecida.

\section{Resultados e discussão}

Conforme já mencionamos, o enquadramento dos argumentos produzidos segundo o padrão de Toulmin nos possibilitou identificar um conjunto de PDD do formador. O processo de enquadramento dos argumentos e de identificação dos PDD é extenso (consta em VIEIRA, 2007) e foi realizado para cada episódio. Deste modo, foi possível compor um quadro de PDD do formador que, segundo o seu escopo comum, foram agrupados em papéis. 
Vieira, R. D.; Nascimento, S. S.

O Quadro 1 ilustra os papéis e os PDD que os compõem, além de fornecer sua respectiva descrição.

Quadro 1. Os papéis e Procedimentos Discursivos Didáticos do formador (adaptado de VIEIRA, 2007, p. 112).

\begin{tabular}{|c|c|c|}
\hline $\begin{array}{l}\text { Papéis do } \\
\text { formador }\end{array}$ & $\begin{array}{l}\text { Procedimentos } \\
\text { Discursivos Didáticos }\end{array}$ & Descrição do procedimento \\
\hline $\begin{array}{l}\text { Avaliador de } \\
\text { pontos de vista }\end{array}$ & $\begin{array}{l}\text { Justificação de um ponto } \\
\text { de vista } \\
\text { Confirmação de ponto } \\
\text { de vista } \\
\text { Reelaboração de um } \\
\text { ponto de vista }\end{array}$ & $\begin{array}{l}\text { Formador imagina possíveis justificativas e evidências que } \\
\text { podem dar suporte a uma opinião } \\
\text { Formador assegura um ponto de vista ou justificativa de } \\
\text { um licenciando } \\
\text { Formador retoma um dado ponto de vista alheio e o } \\
\text { reelabora em sua fala }\end{array}$ \\
\hline $\begin{array}{l}\text { Gerenciador } \\
\text { da discussão }\end{array}$ & $\begin{array}{l}\text { Explicitação de um } \\
\text { ponto de vista } \\
\text { Sumarização de idéias } \\
\text { discutidas } \\
\text { Enunciação de pontos } \\
\text { de vista contraditórios } \\
\text { Elaboração de } \\
\text { feedbacks eliciativos } \\
\text { Interrupção de turnos de } \\
\text { fala dos licenciandos } \\
\text { Estabelecimento da } \\
\text { última palavra }\end{array}$ & $\begin{array}{l}\text { Formador expõe o seu próprio ponto de vista } \\
\text { Formador sintetiza, em sua fala, ideias, pontos de vista e } \\
\text { justificativas anteriores sobre uma dada questão } \\
\text { Formador enuncia dois pontos de vista contraditórios sobre } \\
\text { uma mesma questão } \\
\text { Formador solicita um ponto de vista sobre uma dada } \\
\text { questão ou pede por maior elaboração na fala de um } \\
\text { licenciando } \\
\text { Formador interrompe a fala de um licenciando para avaliar } \\
\text { o que foi dito ou dar sua opinião sobre o assunto em pauta } \\
\text { Formador finaliza a discussão com enunciações que } \\
\text { redirecionam a atenção da turma para outra discussão ou } \\
\text { atividade }\end{array}$ \\
\hline Auscultador & Escuta atenta & $\begin{array}{l}\text { Formador se mantém em silêncio prestando atenção nas } \\
\text { trocas discursivas entre os licenciandos }\end{array}$ \\
\hline
\end{tabular}

A seguir, vamos utilizar, como unidade de análise da dinâmica argumentativa, cinco dos dez PDD apresentados no quadro e indicar de maneira consistente o seu "ligar" ocupado na estrutura discursiva do episódio em que ocorreram.

\section{Fase de abertura}

\section{Procedimentos de enunciação de pontos de vista contraditórios}

e justificação de um ponto de vista

O episódio em que sucederam os Procedimentos analisados ocorreu na nona aula da disciplina pesquisada, teve duração de quatro minutos e foi constituído por 25 turnos de fala. $\mathrm{Na}$ ocasião estavam presentes 16 licenciandos, sendo que a participação na discussão se res- 
tringiu a quatro deles e o formador. O objetivo geral da aula era discutir sobre processos de aprendizagem com base nas ideias de Piaget e relacioná-los com o ensino de Física. O formador propôs inicialmente uma atividade a ser realizada em grupos de dois a três licenciandos, de modo que as seguintes questões fossem respondidas: 1) O que fazemos quando aprendemos coisas novas? 2) Como se dá a aprendizagem humana?

Após discutirem sobre as duas questões, os grupos apresentaram as suas respostas, que foram anotadas na lousa pelo formador. Durante esse processo o formador fez várias intervenções e comentários. Em uma de suas intervenções, ele salientou a função cognitiva de coordenação de ideias e, para ilustrar, desenhou na lousa, como exemplo, o movimento de um corpo lançado verticalmente para cima na superfície da Terra. O episódio teve início a partir da colocação de uma questão pelo licenciando RUI (nas transcrições a seguir e no restante do artigo, a numeração se refere aos turnos de fala, e as expressões que aparecem entre colchetes buscam trazer esclarecimentos de sentido em função do contexto discursivo anterior, além de explicitarem comentários do transcritor sobre outros elementos observados):

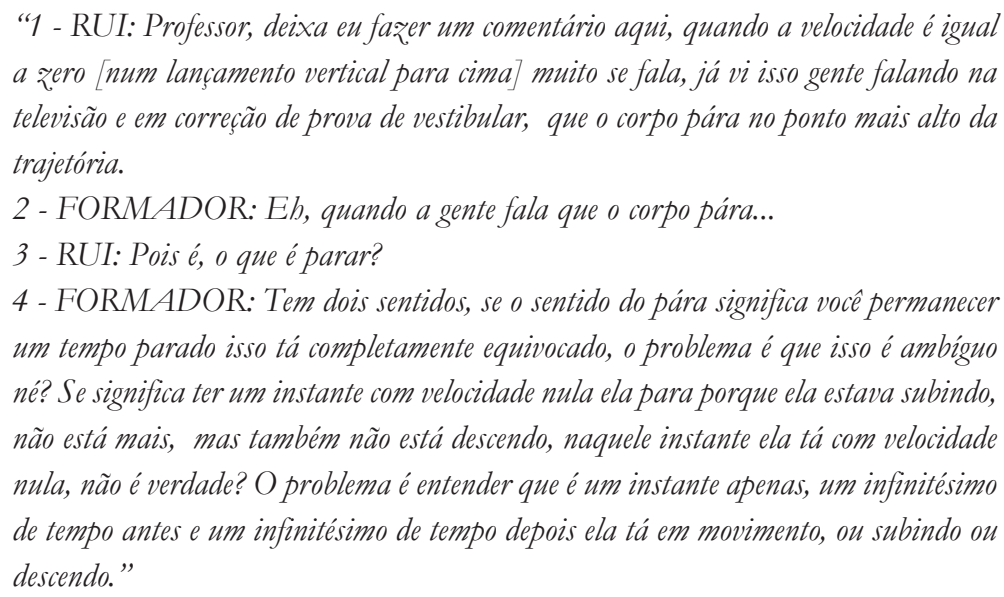

No turno de fala $4^{3}$, em resposta ao questionamento do licenciando RUI, o formador explicita que podem existir dois sentidos para o parar (procedimento de "enunciar dois pontos de vista contraditórios"), apresentando duas justificativas para cada um deles (procedimento de "justificação de um ponto de vista").

\footnotetext{
${ }^{3}$ É importante notar a diferença fundamental entre as duas definições (sentidos) de repouso que o formador apresenta neste turno de fala e que são retomadas ao longo de todo o episódio: a primeira definição associa o repouso à velocidade nula apenas, mesmo que em um único instante de tempo; a segunda definição associa o repouso à permanência do corpo em uma mesma posição durante um determinado intervalo de tempo. Assim, neste turno de fala, o formador coloca as bases da discussão, mantendo certa imparcialidade neste momento. Com o avanço da discussão, o formador demonstra concordar com o ponto de vista de que o corpo não para, o que pode ser constatado no seu turno de fala 9 ("Ele não está parado"). Para uma discussão mais detalhada, ver Vieira e Nascimento (2007) e Nascimento e Vieira, (2008).
} 
Deste modo, o formador elabora dois argumentos: um deles a favor do repouso e o outro a favor do movimento de um objeto no ponto mais alto da sua trajetória em um lançamento vertical para cima (NASCIMENTO e VIEIRA, 2008; VIEIRA e NASCIMENTO, 2007).

Como o formador constrói dois argumentos que defendem duas opiniões contraditórias, isso nos leva a considerar, sob critérios de coerência, que ele não concorda com uma das opiniões. Inclusive, no desenvolvimento da discussão, o formador demonstra que não está de acordo com a opinião que defende o repouso do objeto. No entanto, ele justifica ambas de maneira sólida, ou seja, podemos perceber aí uma forma específica de emprego do procedimento de "justificação de um ponto de vista".

Este procedimento, nesta forma específica em que foi empregado pelo formador, nos levou a reconhecê-lo enquanto uma contribuição para se estabelecer um discurso argumentativo com interação dos licenciandos. Tal conexão se justifica em função das características particulares desse procedimento discursivo, em que um argumento é a refutação do outro, ou seja, cada argumento conta com uma refutação. A refutação, por sua vez, de acordo com Toulmin (1958), cumpre o papel de dar os limites de um dado argumento; com isso, compreendemos que a refutação presente na fala de um mesmo interlocutor favorece a relativização de seus pontos de vista, tornando-os mais nivelados, contribuindo para diminuir a assimetria de um em relação ao outro. Esta característica, se considerarmos a posição do formador enquanto interlocutor privilegiado, é de fundamental importância no sentido de evitar aprisionar a opinião dos licenciandos em uma autoridade: a do próprio formador. No momento da construção dos dois argumentos, o formador, de certa forma, abre mão da sua parcialidade (e da sua autoridade) para orientar a discussão de uma maneira mais polifônica, em que dois pontos de vista são explicitados e justificados.

Situando essa discussão na questão dos propósitos pedagógicos, avaliamos que se o formador ou professor deseja que se estabeleça um discurso com vistas à consideração de conhecimentos preestabelecidos - os da ciência - então, a forma com que foram empregados os dois PDD aqui apresentados pode servir a tal propósito, evitando trazer uma voz de autoridade, ao mesmo tempo em que também restringe a polifonia a determinados aspectos, no caso aqui analisado, às definições de repouso. Portanto, esses PDD associam-se ao momento de abertura da situação argumentativa, em que o formador lida com uma situação argumentativa em potencial e para a qual dá todo um suporte discursivo para o seu desenvolvimento segundo um eixo bem definindo.

\section{Fase de desenvolvimento}

\section{Procedimento de confirmação de um ponto de vista}

Conforme demonstramos em outro trabalho (NASCIMENTO, PLANTIN e VIEIRA, 2008), uma das formas do formador validar os argumentos dos licenciandos é por meio da repetição e da confirmação. O trecho de transcrição a seguir exemplifica nossas considerações (o texto entre barras representa falas simultâneas do formador):

"5 - RUI: Pois é, porque o conceito intuitivo, clássico que a pessoa leva, que parar demanda um tempo com ela na mesma posição |FORMADOR - exato| e na verdade isso não ocorre, |FORMADOR - isso não ocorre | num tem nenbum tempo 
|FORMADOR - não| que ela tá na mesma posição |FORMADOR - não, | se você fizer o limite ali, $\mid F O R M A D O R$ - correto $\mid$ o limite tende a zero ali $\mid F O R$ $M A D O R$ - correto I isso não tem, então esta questão é interessante, parar no ponto mais alto, ela não pára no ponto mais alto."

Enquanto o formador repete e confirma a fala de RUI, desloca-se ao mesmo tempo para próximo dele (o formador estava inicialmente bastante afastado de RUI), demonstrando, desta forma, interesse por suas colocações e reconhecimento da sua dominância discursiva em relação aos outros licenciandos naquele momento.

Empiricamente, o procedimento de confirmação esteve cronologicamente associado ao desenvolvimento da argumentação, uma vez que as bases e os limites da discussão já haviam sido colocados pelo formador com os dois PDD analisados anteriormente. Podemos justificar teoricamente a conveniência deste procedimento na fase de desenvolvimento se entendermos que o formador, ao validar os argumentos de RUI, contribui para o estabelecimento de um ponto de vista preferencial, sem ainda, no entanto, definir de maneira decisiva o fim da discussão. Quer dizer, o formador sai da sua posição de "nentralidade" e assume um ponto de vista específico, de forma que a sua parcialidade assumida propicia o desenvolvimento das contradições inicialmente colocadas na fase de abertura, conforme pode ser notado pela fala de NEY:

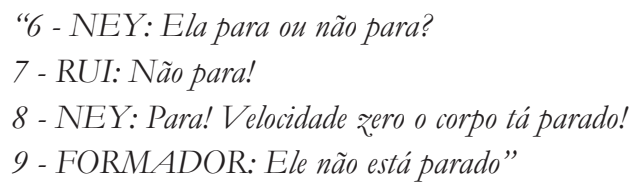

Com isso, interpretamos que o procedimento intensifica as contradições colocadas inicialmente, justamente porque o formador passa a ser parcial com o ponto de vista de RUI. Podemos dizer que, neste momento, as parcialidades emergem e, consequentemente, colaboram para que outras também se manifestem, como é o caso para a entrada de NEY na discussão. Portanto, as contradições iniciais e o eixo argumentativo passam a ser potencializados e a discussão torna-se mais acirrada, com a inclusão de mais participantes no debate. Tais características situam esse momento na fase de desenvolvimento da argumentação.

\section{Procedimentos de explicitação de um ponto de vista e justificação de um ponto de vista}

No turno de fala 8, apresentado acima, NEY discorda de RUI e do formador, argumentando que se a velocidade é nula, então o objeto está parado.

Após justificativas, por parte do formador e de RUI, de que o objeto não está parado, e NEY argumentar o contrário, ele passa então a questionar o status de algo reificado na comunidade de licenciandos em física: a velocidade nula da bola no ponto mais alto da trajetória. $\mathrm{O}$ trecho a seguir ilustra esse momento inusitado:

"19 - NEY: Então a velocidade não é zero!

20 - FORMADOR: A velocidade é zero, naquele instante a velocidade é zero. 
21- NEY: Não tem jeito [licenciandos falam ao mesmo tempo na tentativa de justificar que a velocidade é zero].

22 - FORMADOR: Veja, a velocidade é zero porque graficamente você até enxerga isso fformador recorre ao desenho feito na lousa da velocidade pelo tempo - gráfico linear decrescente que passa pela velocidade zero num instante de tempo e continua a decrescer nos instantes de tempo subseqüentes] a velocidade vai decrescendo e a partir de um determinado momento ela aumenta mas no sentido inverso, que então ela passa por uma velocidade nula entre uma coisa e outra, não é? Num instante, mas ela não para, se você pegar qualquer tempinho depois qualquer tempinho antes, se vocêpegar a integral disso aqui ela andou, algum deslocamento teve aí."

É evidente. pela transcrição. que realmente o conhecimento da velocidade nula é reificado (tanto que vários licenciandos passam a falar ao mesmo tempo para justificar que a velocidade de fato é nula, conforme pode ser atestado no turno 21). Ao que tudo indica, NEY não consegue separar o conceito de movimento do de velocidade instantânea e, com isso, deduz que, se há movimento, como o FORMADOR e RUI afirmam, então não pode haver velocidade nula. Ou seja, ele inverte a ordem de causalidade do argumento do turno 8 e acaba deduzindo o contrário do que defendeu no início. $\mathrm{O}$ formador, atento a essa contradição discursiva de NEY e à sua incorreção quanto ao conhecimento físico, que até então era tomado como certo e compartilhado, explicita e justifica um ponto de vista: a velocidade nula do objeto.

Com isso, o formador desloca a argumentação para outro foco: ele enuncia e argumenta que a velocidade é nula, não para justificar que o objeto está parado, mas porque está atento a lacunas de conhecimento físico do licenciando NEY. Podemos dizer que, neste ponto, tais PDD colaboram para fechar uma zona argumentativa secundária e incidental, para só, então, voltar ao foco argumentativo principal, que é a questão do movimento ou repouso do objeto no ponto mais alto da trajetória.

Os dois PDD, neste caso, claramente se situam na fase de desenvolvimento, já que cumprem a função de fechar uma "ramificação" que surgiu da discussão principal, sendo que tal ramificação, aos olhos do formador, deve ser bem esclarecida e estabelecida (dado retirado da segunda entrevista realizada com o formador). Isso nos remete ao fato de que a argumentação orientada didaticamente deve ter um foco, ou então passamos a ter várias aberturas argumentativas que não se fecham, e, consequentemente, dispersões. Ou seja, aqui os dois PDD servem para diminuir a polissemia que, por sua vez, poderia levar a uma dispersão argumentativa quanto ao foco principal. É interessante notar que, na fase de abertura, a polissemia é bem-vinda, justamente para criar terreno para a argumentação. Agora, neste ponto, a polissemia é reduzida como forma de evitar dispersões. 


\section{Fase de fechamento}

\section{Procedimento de estabelecer a última palavra}

O formador, após aproximadamente quatro minutos de discussão sobre a questão do movimento ou repouso do objeto, resolve redirecionar a atenção dos licenciandos para ao tema imediatamente anterior à discussão: os processos de aprendizagem e a coordenação de ideias no processo de descrever e analisar o movimento vertical de um objeto sob a ação gravitacional. Para tanto, ele se vale de sua posição assimétrica e estabelece a ultima palavra para a discussão:

"25 - FORMADOR: Veja que o que eu tô querendo chamar a atenção fformador faz. um som (shhhh!) no sentido de pedir silêncio] é que na hora de descrever essa bistória nós usamos uma coordenação de uma série de idéias de distância, de tempo, de dividir isso em infinitésimos, de vetores de representações de gráficos, não é isso? de taxas de variação, ou seja, usamos uma coordenação de idéias pra dar sentido, um sentido novo pra esse fenômeno tão familiar, tão trivial né? De lançar um objeto para cima e deixa-lo cair, né? Não é assim?"

O formador realiza o procedimento de fechar a discussão, mesmo sem haver consenso (e, de fato, não houve, pois NEY não se convenceu de que o objeto não está parado), quando pede silêncio por meio de uma onomatopéia, aumenta o tom de voz e estabelece em sua fala uma mudança de tema. Assim, esses três recursos funcionam conjuntamente para o "estabelecimento da última palavra". O formador alcança sucesso, uma vez que, na sequência, a discussão sobre o movimento ou repouso é fechada e estabelece-se uma nova discussão, desta vez envolvendo uma questão pedagógica.

$\mathrm{Na}$ segunda entrevista realizada com o formador, foi possível entender por que ele resolveu fechar a discussão do movimento ou repouso do objeto naquele momento, conforme destaca o trecho da entrevista: "[...] O que havia para aprender com aquela situação já havia sido aprendido, e que passou a ser muito opinião pessoal de dizer isso ou aquilo em sala de aula [...]".

\section{A estrutura discursiva procedimental argumentativa do formador no episódio analisado}

Com base na descrição e análise dos PDD, é possível esquematizá-los numa estrutura integrada e relacional, a qual torna possível perceber como a dinâmica argumentativa é gerenciada e controlada pelo formador. A Figura 1 representa essa estrutura. 
Vieira, R. D.; Nascimento, S. S.

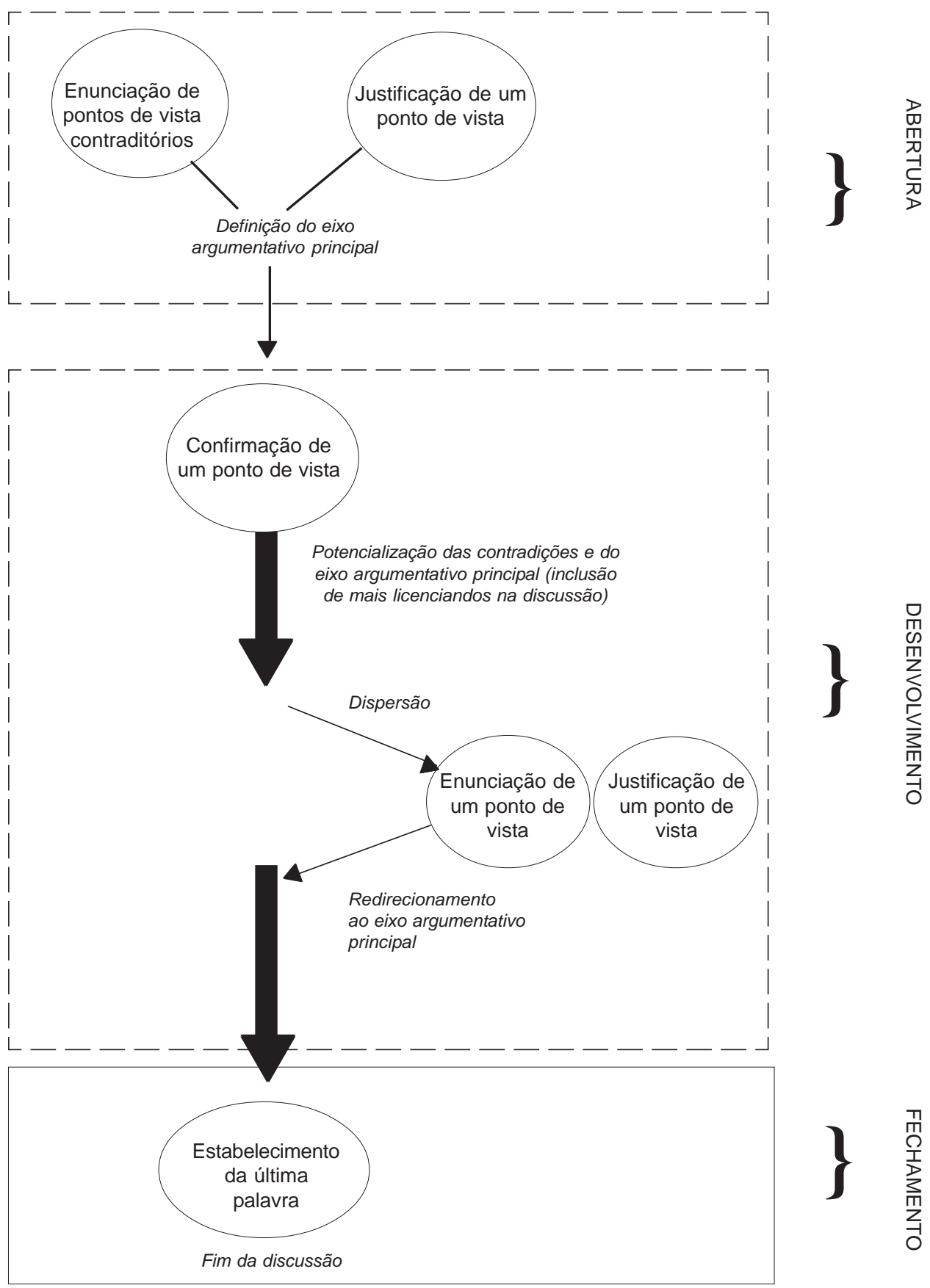

Legenda:

Textos em negrito dentro dos círculos - Procedimentos discursivos didáticos do formador

Textos em itálico e setas - modificações no discurso produzido

Figura 1. Um esquema dinâmico da estrutura procedimental argumentativa do formador no episódio analisado. 


\section{Conclusões}

Com base nas discussões de cinco Procedimentos Discursivos Didáticos (PDD) específicos do formador, no episódio selecionado, foi possível integrá-los numa estrutura discursiva relacional, a qual explicita as modificações discursivas introduzidas por meio desses Procedimentos. Com isso, foi possível apresentar um arcabouço discursivo procedimental contextualmente situado.

A ideia de estabelecer conhecimentos pedagógicos de ordem procedimental não é nova. Santos, Mortimer e Scott (2001) revelam, em seu estudo, alguns procedimentos que o professor pode tomar para incentivar a argumentação. Os autores apontam também para "a necessidade do desenvolvimento de intervenções pedagógicas pelo professor que contribuam para aumentar a capacidade argumentativa dos alunos" (p. 1). Nesse sentido, outros estudos na Educação Básica têm evidenciado formas de analisar o discurso em aulas de ciências e de relacionar tais discursos ao cumprimento de diferentes propósitos do professor por meio de determinadas condutas discursivas dele, como, por exemplo, o uso do padrão IRF e IRA (MORTIMER e SCOTT, 2002; CAPPECCHI e CARVALHO, 2004; AGUIAR JR e MORTIMER, 2005). Entretanto, pouca pesquisa tem sido investida nesse sentido na formação de professores. Outro aspecto importante a ser mencionado é que as pesquisas da área tradicionalmente têm analisado o discurso segundo padrões de interação, enquanto procuramos categorias de análise que os compreendem e ultrapassam e que são especificamente relacionadas às ações do professor, como os PDD que aqui analisamos. Neste caso, os PDD foram considerados enquanto uma unidade discursiva de ação do formador, mesmo que composta de diversos padrões de interações e de subcategorias. Conforme demonstramos neste trabalho, a utilização de tal unidade permitiu associar ações do formador, dinâmica discursiva e propósitos pedagógicos numa estrutura dinâmica e relacional.

Assim, avaliamos que as discussões e os resultados ora apresentados podem colaborar para a ampliação das possibilidades de condução e gerenciamento do discurso em sala de aula, em particular nas situações argumentativas na formação inicial de professores de física. Nossa posição se justifica por reconhecermos os PDD analisados como exemplares, conforme atestam as suas repercussões no discurso do episódio argumentativo que analisamos. $\mathrm{O}$ caráter exemplar já era esperado, posto que os PDD surgiram da prática de um formador experiente e informado pelos estudos do discurso em sala de aula.

Cumpre mencionar que os PDD apresentados são fluidos, ou seja, podem servir ao cumprimento de outros propósitos além daqueles aqui especificados. Daí a relevância de situálos no contexto em que aparecem, de forma a lhes investir de um significado que pode radicalmente mudar quando da mudança de contexto e, até mesmo, quando da mudança do domínio de conteúdo discutido. Foi possível, inclusive, verificar essa fluidez para o episódio aqui analisado: o PDD de "justificar um ponto de vista" se investiu, inicialmente, da função de favorecer a argumentação, sendo que, na sua segunda utilização, veio a restringi-la. Quer dizer, em momentos diferentes da dinâmica argumentativa, formas distintas de utilização de um mesmo PDD serviram tanto para aumentar a polissemia quanto para restringi-la.

Levando em conta tais considerações, sugerimos, por fim, em situações de formação de professores, a necessidade de pesquisas que tenham como objeto de estudo o discurso em sala de aula, de modo que visem ampliar o conhecimento sobre os PDD de que o formador 
Vieira, R. D.; Nascimento, S. S.

pode lançar mão no momento de gerenciar o discurso em contextos específicos, tanto em situações argumentativas quanto em outras situações, como as narrativas, descritivas, e explicativas. Tais iniciativas são de relevante importância, uma vez que um conhecimento mais completo dos PDD, em todos os níveis de ensino e em diferentes contextos de um mesmo espaço de formação, poderia compor um conhecimento pedagógico situado capaz de servir de referência para os professores em situações discursivas concretas de sala de aula.

\section{Referências}

AGUIAR JR., O. G.; MORTIMER, E. F. Tomada de consciência de conflitos: análise da atividade Discursiva em uma Aula de Ciências. Investigações em Ensino de Ciências, Porto Alegre, v. 10, n. 2, 2005. Disponível em: <http://www.if.ufrgs.br/public/ensino/ vol10/n2/v10_n2_a3.htm>. Acesso em: 3 jul. 2007.

ALEXANDRE, M. P. J.; AGRASO, M. F. A argumentação sobre questões sociocientíficas: processos de construção e justificação do conhecimento em sala de aula. Educação em Revista, Belo Horizonte, n. 43, p. 13-35, 2006.

ANDRÉ, M. E. D. A. (Org.). Formação de professores no Brasil (1990-1998). Brasília: MEC/Inep/Comped, 2002.

BAKHTIN, M. M. Estética da criação verbal. 3. ed. São Paulo: Martins Fontes, 2000.

BILLIG, M. Arguing and thinking: a rhetorical approach to social psychology. Cambridge: Cambridge University Press, 1996.

CANDELA, A. Prácticas discursivas en el aula y calidad educativa. Revista Mexicana de Investigación Educativa, México, v. 4, n. 8, p. 273-298, 1999.

CAPECCHI, M. C. V. M. Argumentação numa aula de Física. In: CARVALHO, A. M. P. (Org.). Ensino de Ciências: unindo a pesquisa e a prática. São Paulo: Pioneira Thomson Learning, 2004. p. 59-76.

FREITAS, C. A. Imagens faladas: estudo da dinâmica discursiva, uso e interpretação de imagens em aulas de biologia. 2002. 127f. Dissertação (Mestrado em Educação) - Faculdade de Educação, Universidade Federal de Minas Gerais, Belo Horizonte, 2002.

KUHN, D. Science as argument: implications for teaching and learning scientific thinking. Science Education, New York, v. 77, n. 3, p. 319-337, 1993.

MORTIMER, E. F.; SCOT'T, P. Atividade discursiva nas salas de aula de ciências: uma ferramenta sociocultural para analisar e planejar o ensino. Investigações em Ensino de Ciências, Porto Alegre, v. 7, n. 3, p. 3, 2002. Disponível em: <http://www.if.ufrgs.br/ public/ensino/vol7/n3/v7_n3_a7.htm >. Acesso em: 29 abr. 2007.

MUNFORD, D. et al. Práticas discursivas e o ensino-aprendizagem do professor de ciências: tecendo relações entre argumentação e objetivos pedagógicos na formação inicial. 
Uma visão integrada dos procedimentos ...

In: ENCONTRO NACIONAL DE PESQUISADORES EM ENSINO DE CIÊNCIAS, 5., 2005, Bauru. Atas ... Bauru: Abrapec, 2005. 1 CD-ROM.

NASCIMENTO, S. S.; PLANTIN, C.; VIEIRA, R. D. A validação de argumentos em sala de aula: um exemplo a partir da formação inicial de professores de física. Investigações em ensino de Ciências, Porto Alegre, v. 13, n. 2, 2008. Disponível em: <http://www.if.ufrgs.br /ienci/artigos/Artigo_ID181/v13_n2_a2008.pdf>: Acesso em: 29 ago. 2008.

NASCIMENTO, S. S.; VIEIRA, R. D. Contribuições e limites do padrão de argumento de Toulmin aplicado em situações argumentativas de sala de aula de ciências. Revista Brasileira de Pesquisa em Educação em Ciências, Belo Horizonte, v. 8, n. 2, p. 1-20, 2008. Disponível em: <http://www.fae.ufmg.br:8080/abrapec/revista/index.html>. Acesso em: 22 out. 2008.

SANTOS, W. L. P.; MORTIMER, E, F.; SCOTTT, P. H. A argumentação em discussões sócio-científicas: reflexões a partir de um estudo de caso. Revista Brasileira de Pesquisa em Educação em Ciências, Porto Alegre, v. 1, n. 1, p. 140-152, 2001.

TOULMIN, S. The uses of argument. Cambridge: Cambridge University Press, 1958.

VAN EEMEREN, F. H.; GROOTENDORST, R.; KRUIGER, T. Handbook of argumentation theory: a critical survey of classical backgrounds and modern studies. Dordrecht: Foris Publications Holland, 1987.

VIEIRA, R. D. Situações argumentativas na abordagem da natureza da ciência na formação inicial de professores de Física. 2007. 173f. Dissertação (Mestrado em.Educação) - Faculdade de Educação, Universidade Federal de Minas Gerais, Belo Horizonte, 2007.

VIEIRA, R. D.; NASCIMENTO, S. S. A argumentação no discurso de um professor e seus estudantes sobre um tópico de mecânica newtoniana. Caderno Brasileiro de Ensino de Física, Florianópolis, v. 24, n. 2, p. 174-193, 2007.

Uma proposta de critérios marcadores para identificação de situações argumentativas em salas de aula de ciências. Caderno Brasileiro de Ensino de Física, Florianópolis, v. 26, n. 1, p. 81-102, 2009.

VILLANI, C. E. P. As práticas discursivas argumentativas de alunos do Ensino Médio no laboratório didático de física. 2002. 187f. Dissertação (Mestrado em Educação) Faculdade de Educação, Universidade Federal de Minas Gerais, Belo Horizonte, 2002.

.; NASCIMENTO, S. S. A argumentação e o ensino de ciências: uma atividade experimental no laboratório didático de Física do Ensino Médio. Investigações em Ensino de Ciências, Porto Alegre, v. 8, n.3, p. 1-24, 2003.

VYGOTSKY, L. S. Pensamento e linguagem. 2. ed. São Paulo: Martins Fontes, 2000.

Artigo recebido em março de 2008 e aceito em agosto de 2009. 